\title{
GAMBARAN SENSE OF COMMUNITY PADA KARYAWAN BAGIAN ADMINISTRASI DI UNIVERSITAS MUHAMMADIYAH SIDOARJO
}

\author{
Effy Wardati Maryam ${ }^{1}$ \\ ${ }^{1}$ Fakultas Psikologi Universitas Muhammadiyah Sidoarjo, Sidoarjo, Indonesia
}

\begin{abstract}
This study aims to determine the description of a sense of community in the administrative employees at the Universitas Muhammadiyah Sidoarjo. Subjects in this study were employees of the administration in UMSIDA, amounting to 51 person, with the technique of determining the sample using saturated sampling. The data collection tool uses a sense of community scale by adapting 24 items of Sense of Community Index Version Two (SCI-2) which refers to the sense of community theory proposed by McMillan and Chavis. Data analysis techniques in this study using descriptive statistical techniques. The results of data analysis show that the sense of community in the administrative staff at Muhammadiyah University of Sidoarjo generally are in the medium category. Whereas if viewed from the existing dimensions, shared emotional connection dimension get the highest score compared with other dimensions.
\end{abstract}

Keywords: sense of community, administration employee

\begin{abstract}
ABSTRAK
Penelitian ini bertujuan untuk mengetahui gambaran sense of community pada karyawan bagian administratif di Universitas Muhammadiyah Sidoarjo. Subjek dalam penelitian ini adalah karyawan bagian administrasi di UMSIDA yang berjumlah 51 orang, dengan teknik penentuan sampel menggunakan sampling jenuh. Alat pengumpulan datanya menggunakan skala sense of community dengan mengadaptasi 24 item Sense of Community Index Version Two (SCI-2) yang mengacu pada teori sense of community yang dikemukakan oleh McMillan dan Chavis. Teknik analisis data dalam penelitian ini menggunakan teknik statistik deskriptif. Hasil analisis data menunjukkan bahwa sense of community pada karyawan bagian administrasi di Universitas Muhammadiyah Sidoarjo secara umum berada pada kategori sedang. Sedangkan jika dilihat dari dimensi yang ada, dimensi shared emotional connection memperoleh skor tertinggi dibandingkan dengan dimensi yang lain.
\end{abstract}

Kata Kunci: sense of community, karyawan bagian administrasi 


\section{PENDAHULUAN}

Interaksi yang terjalin selama beberapa waktu pada sebuah lingkungan atau komunitas, akan membentuk sebuah ikatan di antara para anggotanya. Interaksi yang berlangsung dalam beberapa waktu pada sebuah kelompok atau komunitas, akan membentuk jalinan atau ikatan di antara anggotanya. Ikatan yang semakin kokoh antar anggota dapat memberikan pengaruh terhadap munculnya perubahan perilaku yang memperlihatkan bahwa komunitas atau kelompok tersebut memiliki arti yang mendalam bagi individu (Amin, 2015). Inilah yang dinamakan dengan sense of community, yaitu adanya perasaan bahwa anggota komunitas memiliki keterikatan, perasaan bahwa anggota memiliki arti bagi anggota lain dan kelompoknya, serta adanya keyakinan bersama bahwa kebutuhan anggota bisa terpenuhi melalui komitmen para anggota untuk bersama (McMillan \& Chavis, 1986)

Sarason menyatakan bahwa sense of community merupakan persepsi mengenai adanya kesamaan dengan orang lain, adanya saling ketergantungan dengan orang lain, keinginan untuk mempertahankan interdependensi dengan cara memberikan atau melakukan sesuatu untuk orang lain, dan adanya perasaan bahwa seseorang menjadi bagian dari kelompoknya (Patria, 2012). Novia menambahkan bahwa semakin tinggi derajat sense of community yang dimiliki seseorang, maka semakin besar kemungkinan orang tersebut untuk tetap mempertahankan keanggotaannya di dalam sebuah komunitas (Amin, 2015). Lebih lanjut dikatakan bahwa sense of community sangat diperlukan bagi sebuah komunitas sebagai alat untuk mempertahankan kelangsungan hidup komunitas.

\section{Menurut McMillan \& Chavis} (1986), sense of community memiliki empat komponen atau aspek yang membentuk komunitas. Pertama membership (keanggotaan), yaitu perasaan memiliki atau berbagi perasaan saling terikat satu sama lain karena menjadi bagian dari sebuah komunitas. Aspek kedua adalah influence (pengaruh), yakni adanya perasaan anggota bahwa ia dipengaruhi oleh komunitasnya dan individu juga mempengaruhi komunitasnya. Aspek ketiga yaitu integration and fullfillment of need (reinforcement of needs), merupakan perasaan dimana anggota merasa bahwa kebutuhannya terpenuhi melalui sumbersumber yang berasal dari keanggotaan dalam kelompoknya. Aspek yang keempat adalah shared emotional connection, yaitu adanya perasaan bahwa kejadian penting dalam komunitas dilakukan pada waktu dan 
tempat secara bersama-sama dengan anggota lainnya, atau komitmen di antara anggota kelompok untuk saling berbagi (sejarah, waktu, pengalaman). Keempat elemen tersebut saling berinteraksi dan memberikan kontribusi terhadap munculnya rasa memiliki individu pada komunitas.

Masing-masing anggota dalam sebuah kelompok harus memiliki sense of community ini agar kelompoknya tetap bertahan dan semakin kuat atau kokoh. Munculnya sikap apatis dan individualis di antara anggota sebuah komunitas, dapat menjadi faktor penghambat kualitas interaksi dengan anggota lainnya, sehingga mempengaruhi kenyamanan anggota, yang akhirnya berdampak pada keberlanjutan sebuah kelompok atau komunitas (Amin, 2015). Penelitian yang dilakukan oleh Martinez (2017) menunjukkan bahwa rendahnya sense of community anggota terhadap kelompok, mendorong munculnya kejenuhan terhadap kelompok yang pada akhirnya anggota tidak memberikan kontibusi yang optimal terhadap kelompok sehingga mempengaruhi keberlangsungan kelompok.

Universitas Muhammadiyah Sidoarjo (UMSIDA) merupakan salah satu universitas swasta di Jawa Timur yang saat ini tumbuh dengan pesat. Sejak tahun 2010 hingga saat ini UMSIDA memperoleh berbagai penghargaan, antara lain memperoleh status "Terakreditasi Institusi (Universitas)" dari Badan Akreditasi Nasional Perguruan Tinggi (BAN-PT), sebagai "Perguruan Tinggi yang memiliki sistem penjaminan mutu internal terbaik", dan sebagai "Perguruan Tinggi Swasta yang berhasil memperoleh tiga penilaian bidang kelembagaan dan tata kelola, penelitian dan pengabdian kepada masyarakat serta kemahasiswaan". UMSIDA memiliki komitmen untuk menjadikan "Perguruan Tinggi Bermutu Tingkat Nasional tahun 2020". Salah satu upaya yang bisa dilakukan untuk mewujudkan komitmen tersebut, yaitu dengan meningkatkan kualitas interaksi dan rasa kebersamaan di antara warga UMSIDA, termasuk di dalamnya pelaksana administratif atau biasa disebut dengan karyawan administratif di lingkungan UMSIDA. Karyawan administratif sebagai salah satu elemen di lingkungan UMSIDA selain dosen dan mahasiswa, memiliki peranan yang sangat signifikan dalam menjaga atau mempertahankan dan mengembangkan UMSIDA hingga saat ini. Ikatan yang terjalin dengan kuat antara karyawan administratif di UMSIDA dapat mempengaruhi perubahan perilaku yang menandakan bahwa UMSIDA merupakan 
komunitas yang memiliki makna mendalam bagi masing-masing anggota.

Berdasarkan hasil penelitian yang dilakukan oleh Falatehan (2017), diperoleh hasil bahwa sense of community merupakan faktor kuat yang mempengaruhi munculnya partisipasi anggota terhadap program kelompok. Dengan adanya sense of community yang kuat, maka menimbulkan dorongan yang kuat pada anggota kelompok untuk berpartisipasi dalam berbagai program yang ditetapkan oleh kelompok dalam rangka untuk menjaga keberlangsungan kelompok dan mencapai tujuan kelompok. Oleh karena itu, sebagai salah satu upaya untuk mencapai tujuan bersama UMSIDA serta untuk menjaga keberlangsungan dan kekokohan UMSIDA, maka masing-masing anggota dalam lingkungan UMSIDA termasuk di dalamnya karyawan bagian administratif, perlu memiliki sense of community yang tinggi. Berdasarkan hal inilah, maka penelitian ini dilakukan untuk melihat gambaran sense of community yang dimiliki oleh karyawan bagian administratif di UMSIDA.

\section{METODE PENELITIAN}

Penelitian ini merupakan penelitian kuantitatif dengan tipe penelitian deskriptif. Subjek dalam penelitian ini adalah seluruh karyawan administratif tetap di UMSIDA yang berjumlah 64 orang. Penentuan sampel dalam penelitian ini menggunakan teknik sampling jenuh atau sensus (Sugiyono, 2009), yaitu menggunakan semua anggota populasi sebagai sampel penelitian. Seluruh subjek tersebut sebagai subjek try out sekaligus subjek penelitian karena dalam penelitian ini menggunakan try out terpakai. Pencantuman nama UMSIDA dalam penelitian ini telah memperoleh persetujuan secara tertulis.

Skala yang digunakan untuk mengumpulkan data dalam penelitian ini adalah the sense of community index version two (SCI-2) yang disusun berdasarkan teori sense of community yang dikemukakan oleh McMillan dan Chavis (1986), dengan aspek-aspeknya meliputi keanggotaan (membership), pengaruh (influence), integrasi dan pemenuhan kebutuhan (integration and fullfillment of need), serta adanya hubungan emosional bersama (shared emotional connection). Skala ini memiliki 24 item, dengan reliabilitas skala yang ditunjukkan oleh koefisien alpha sebesar 0,94 (standar reliabilitas $>0,60$ ) yang menunjukkan bahwa skala sense of community tergolong reliabel dan validitas item memiliki skor koefisien alpha berkisar 
0,79 sampai 0,86 (standar $r_{i t}>0,25$ ) yang berarti semua item valid.

Teknik yang digunakan untuk melakukan analisis data dalam penelitian ini menggunakan teknik statistik deskriptif. Menurut Sugiyono (2009), teknik ini digunakan untuk menganalisis data dengan cara mendeskripsikan atau menggambarkan data yang telah terkumpul sebagaimana adanya tanpa bermaksud membuat kesimpulan yang berlaku untuk umum atau generalisasi. Adapun langakah-langkah analisis data dalam penelitian ini sebagai berikut :

1. Sebelum skala digunakan untuk penelitian, dilakukan adaptasi skala dari bahasa Inggris ke bahasa Indonesia

2. Dilakukan penyebaran skala kepada subjek penelitian sebanyak 64 orang

3. Setelah terkumpul semua skala yang sudah terisi oleh subjek penelitian, kemudian hasil skala ditabulasi dan dimasukkan ke dalam Microsoft Exel dengan memasukkan semua data yang ada dalam skala, meliputi nomer subjek, unit kerja, jenis kelamin, pendidikan, masa kerja di UMSIDA, skala sense of community (SoC), dan faktor-faktor yang mempengaruhi SoC (melalui open ended quistionare).
4. Hasil tabulasi data berbentuk angka (untuk skala SoC) dan kalimat (open ended quistionare)

5. Data yang berbentuk angka pada skala sense of community total dilakukan dengan cara deskriptif statistik, melalui langkah-langkah sebagai berikut:

a. Mencari nilai minimal dari total SoC pada seluruh subjek penelitian

b. Mencari nilai maksimal dari total SoC pada seluruh subjek penelitian

c. Mencari nilai mean hipotetik dengan rumus $1 / 2$ (skor minimal + skor maksimal)

d. Mencari nilai Standard Deviasi (SD) hipotetik dengan rumus (skor maksimal-skor minimal)/6

e. Hasil mean hipotetik dan SD hipotetik dimasukkan ke dalam rumus kategorisasi untuk mencari frekuensi dan persentase pada tiaptiap kategorisasi di tabel 1.

f. Begitu juga pada setiap aspek SoC, namun perhitungan pada setiap aspek menggunakan mean dan SD empirik dan kemudian dimasukkan pada rumus kategorisasi

g. Hasil analisis deskriptif kemudian dibuat dalam bentuk diagram 
Tabel 1. Kategorisasi

\begin{tabular}{|c|c|c|c|c|}
\hline No. & Pedoman & Kategori & Frekuensi & Persentase \\
\hline 1. & $X \geq(\mu+1 \sigma)$ & Tinggi & 0 & $0 \%$ \\
\hline 2. & $(\mu-1 \sigma) \leq X<(\mu+1 \sigma)$ & Sedang & 0 & $0 \%$ \\
\hline 3. & $X<(\mu-1 \sigma)$ & Rendah & 0 & $0 \%$ \\
\hline & & Total & 0 & $0 \%$ \\
\hline
\end{tabular}

Keterangan:

$\mathrm{X}=$ skor subjek

$\mu=$ Rerata (mean) hipotetik

$\sigma=$ Deviasi standar (SD) hipotetik

\section{Analisis dan Interpretasi Data}

Berdasarkan hasil analisis data dengan menggunakan teknik statistik deskriptif, diperoleh hasil sebagai berikut :

1. Gambaran umum sense of community pada karyawan bagian administrasi di UMSIDA

Berdasarkan hasil analisis data terlihat bahwa sebanyak 10 persen dari responden (karyawan bagian administrasi di UMSIDA) memiliki sense of community pada kategori tinggi, 30 persen berada pada kategori sedang, dan 11 persen berada pada kategori rendah. Hal tersebut bisa dilihat dalam gambar 1 .
2. Gambaran perbandingan aspek-aspek sense of community pada karyawan bagian administrasi di UMSIDA

a. Aspek integration and fullfillment of needs (reinforcement of needs)

Berdasarkan hasil analisis data terlihat bahwa untuk aspek reinforcement of needs (penguatan atau pemenuhan kebutuhan dari UMSIDA pada karyawannya), sebanyak 18 persen subjek memperlihatkan respon yang tinggi, 69 persen berada pada kategori sedang, sementara 13 persen subjek berada pada kategori rendah. Hal ini bisa dilihat pada gambar 1 . 


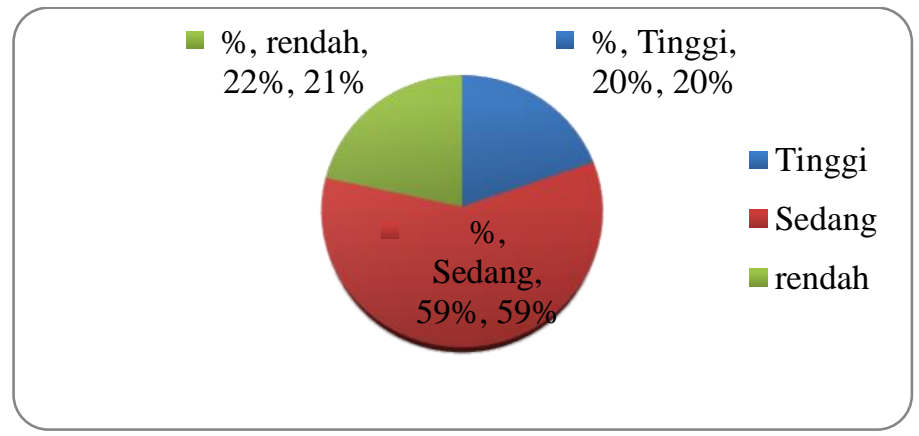

Gambar 1. Sebaran persentase sense of community

b. Aspek membership

Untuk aspek membership, berdasarkan hasil analisis data menunjukkan bahwa sebanyak 20 persen subjek berada pada kategori tinggi, 69 persen subjek di kategori sedang, dan 12 persen berada pada kategori rendah. Hal ini bisa dilihat pada gambar 2 .

c. Aspek influence

Pada aspek influence, sebanyak 18 persen subjek menunjukkan jawaban pada kategori tinggi, 63 persen kategori sedang, dan 20 persen subjek berada pada kategori rendah. Secara lebih detil, bisa dilihat dalam gambar 3

d. Aspek shared emotional connection

Berdasarkan hasil analisis data, diketahui bahwa untuk aspek shared emotional connection, sebanyak 39 persen dari subjek penelitian berada pada kategori tinggi, 43 persen kategori sedang, dan 18 persen subjek pada kategori rendah (gambar 5).

Berdasarkan hasil analisis data yang disajikan pada gambar 6 terlihat bahwa dari empat aspek sense of community yang digunakan sebagai alat ukur dalam penelitian ini, untuk aspek yang berada pada kategori tinggi adalah aspek shared emotional connection, berikutnya aspek membership, diikuti aspek reinforcement of needs dan influence. Untuk kategori sedang, aspek reinforcement of needs dan membership berada pada tingkatan tertinggi yang diikuti oleh aspek influence dan shared emotional connection. Sementara pada kategori rendah, aspek influence menempati posisi tertinggi, diikuti oleh aspek shared emotional connection, reinforcement of needs, dan membership. 


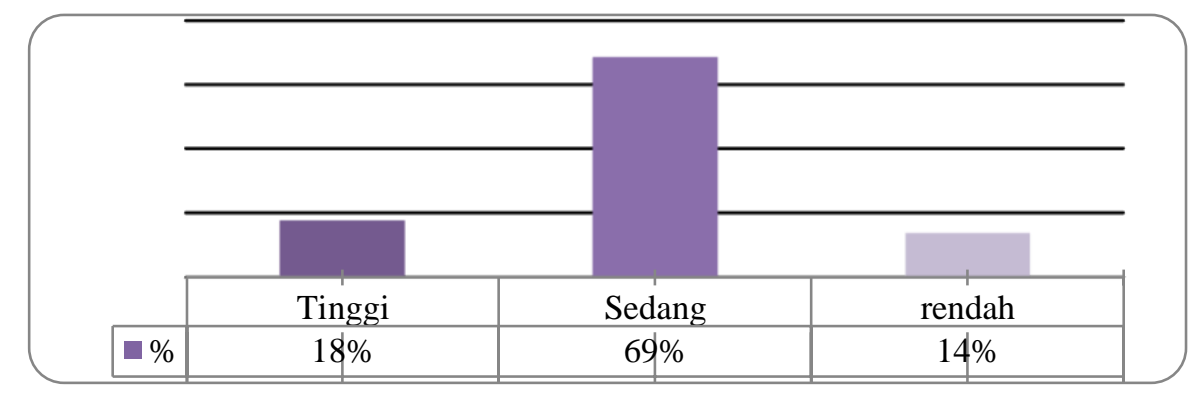

Gambar 2. Kategorisasi aspek reinforcement of needs

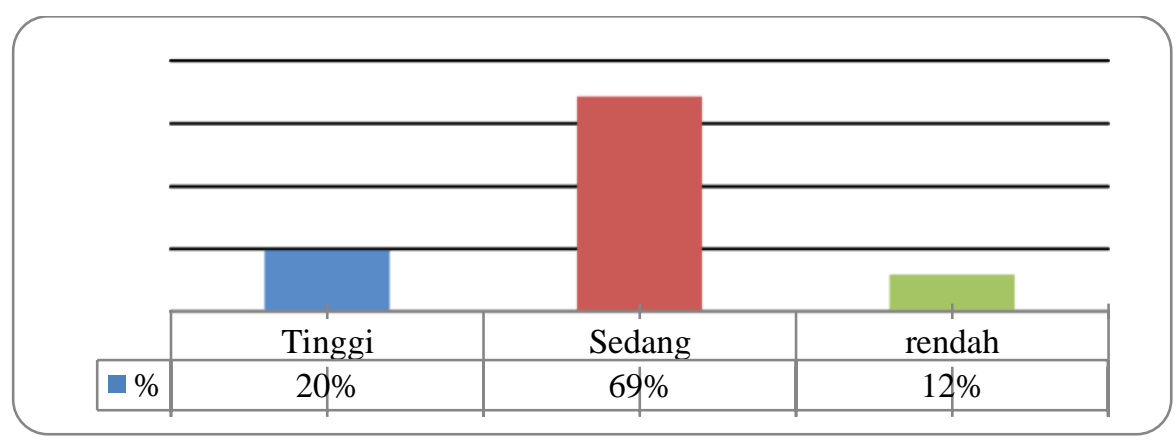

Gambar 3. Kategorisasi aspek membership

\section{PEMBAHASAN}

Hasil analisis data dalam penelitian ini menunjukkan bahwa kondisi sense of community (SoC) pada sebagian besar karyawan bagian administrasi di Universitas Muhammadiyah Sidoarjo (UMSIDA) berada pada kategori sedang (59 persen) dan tinggi (20 persen), hanya 22 persen dari subjek yang berada pada kategori rendah. Hal ini berarti sebagian besar karyawan bagian administrasi di UMSIDA memiliki perasaan keterikatan, merasa berarti bagi anggota yang lain dan juga bagi komunitasnya sendiri, serta yakin bahwa kebutuhannya bisa terpenuhi melalui komitmen bersama dalam komunitasnya. Dengan kondisi sense of community yang cukup tinggi ini, akan mampu mendorong karyawan UMSIDA khususnya pada bagian administrasi untuk bekerja lebih baik, dalam rangka untuk mencapai dan mewujudkan visi UMSIDA "Menjadi Perguruan Tinggi Bermutu Tingkat Nasional Tahun 2020.”

Dimensi atau aspek dari SoC yang berada pada kategori tertinggi dalam penelitian ini adalah aspek shared emotional connection. Hal ini menggambarkan bahwa subjek dalam penelitian ini merasakan adanya hubungan 


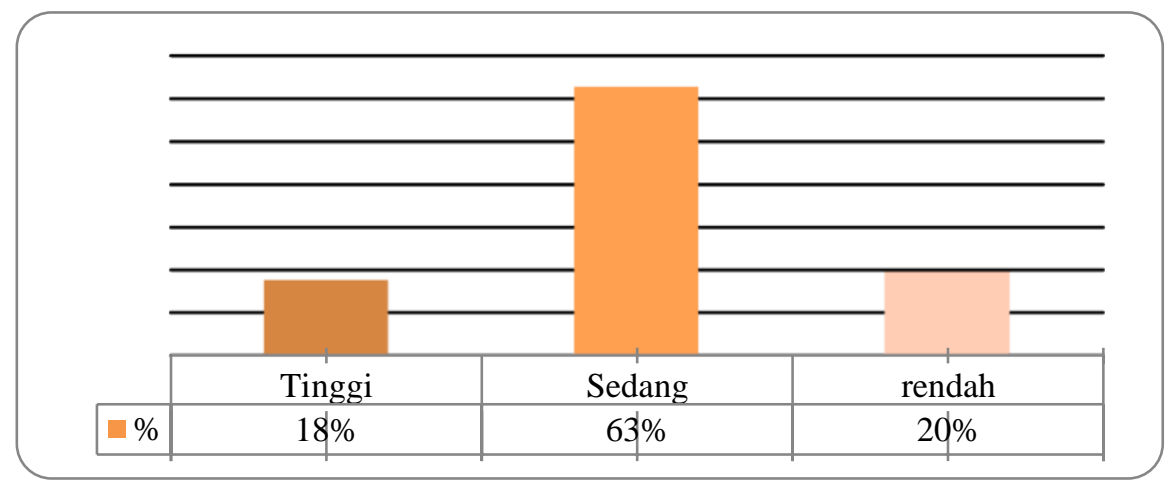

Gambar 4. Kategorisasi aspek influence

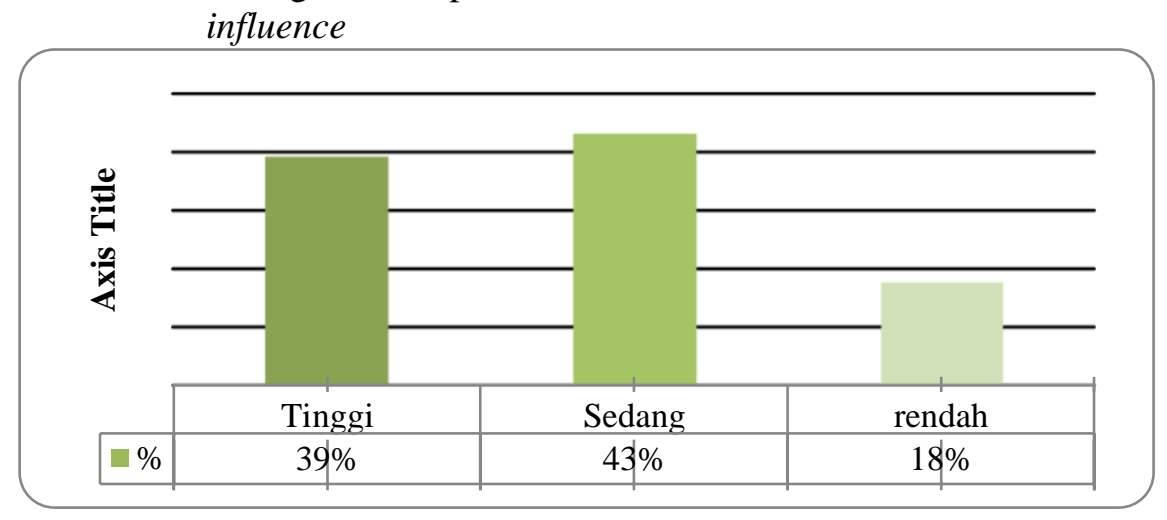

Gambar 5. Kategorisasi aspek shared emotional connection

emosional bersama yang terbentuk dari pengalaman interaksi yang menyenangkan atau positif, berbagi cerita dan kegiatan yang dilakukan bersama-sama. Interaksi anggota yang terjalin dalam berbagai kegiatan tersebut didorong oleh kebiasaan yang selama ini sudah dilakukan dalam komunitas (McMillan \& Chavis, 1986). Prinsip-prinsip penting untuk bisa mencapai shared emotional connection menurut McMillan dan Chavis meliput:
(1) bahwa semakin kerap individu berinteraksi maka mereka menjadi semakin dekat (contact hypothesis), (2) semakin positif pengalaman dan interaksi yang terjalin, maka keterikatan di antara anggota kelompok semakin kuat (quality of interaction), (3) jika interaksi yang terjalin antar anggota ambigu (tidak jelas) dan tugas-tugas kelompok tidak terselesaikan, maka kelekatan (kohesivitas) kelompok akan terhambat (closure to events), (4) kegiatan yang dilakukan secara bersamasama akan membentuk ikatan yang lebih kuat (shared valent event hypothesis), (5) investasi, yang dimaksud di sini adalah 
bahwa investasi menentukan riwayat dan status anggota komunitas. Misalnya anggota yang lebih banyak meluangkan waktu dan tenaga untuk kelompoknya, juga akan lebih banyak terlibat secara emosional terhadap kelompok, (6) penghargaan maupun penghinaan yang ditujukan kepada kelompok secara signifikan akan mempengaruhi ketertarikan kelompok terhadap anggotanya (effect of honor and humiliation on community members), dan (7) spiritual bond, yakni adanya kesempatan untuk merasakan pengalaman keterikatan spiritual bersama-sama anggota komunitas lainnya. Berbagai kegiatan sering diselenggarakan oleh pihak UMSIDA dalam rangka untuk membangun hubungan emosional bersama di antara karyawan khususnya bagian administrasi, misalnya out-bond, Darul Arqam, kajian rutin setiap bulan, dan gathering.

Untuk dimensi SoC yang menempati urutan kedua dalam penelitian ini adalah dimensi atau aspek membership. Membership ini diartikan sebagai sebuah perasaan untuk memiliki dan menjadi bagian dari sebuah komunitas (McMillan \& Chavis, 1968), dimana membership ini memiliki boundaries (batas), yaitu yang membedakan antara individu yang memiliki dan yang tidak memiliki. Boundaries inilah yang akan membuat anggota kelompok merasakan pengalaman emosi yang menyenangkan dalam rangka untuk membangun kedekatan. Selain boundaries, aspek lain yang tercakup dalam membership adalah sense of belonging and identification. Yaitu adanya perasaan diterima dalam kelompoknya, merasa ikut memiliki kelompok, yang akhirnya membuat anggota rela berkorban demi kelompoknya. Lebih dari itu, individu juga terdorong untuk melakukan identifikasi terhadap kelompoknya. Dalam membership juga tercakup personal investment, dimana aspek ini memiliki peranan yang sangat penting untuk membangun perasaan individu terhadap keanggotaannya dalam kelompok dan terhadap sense of community-nya. Dengan adanya personal investment ini, maka membership menjadi lebih bermakna dan bernilai. Usaha yang dilakukan oleh individu untuk menjadi anggota kelompok, merasa diterima di dalam kelompok, dan hadirnya simbol yang mempermudah untuk memahami komunitas akan mendorong semakin kuatnya sense of community sehingga muncul kemauan untuk berkorban demi kelompoknya. 


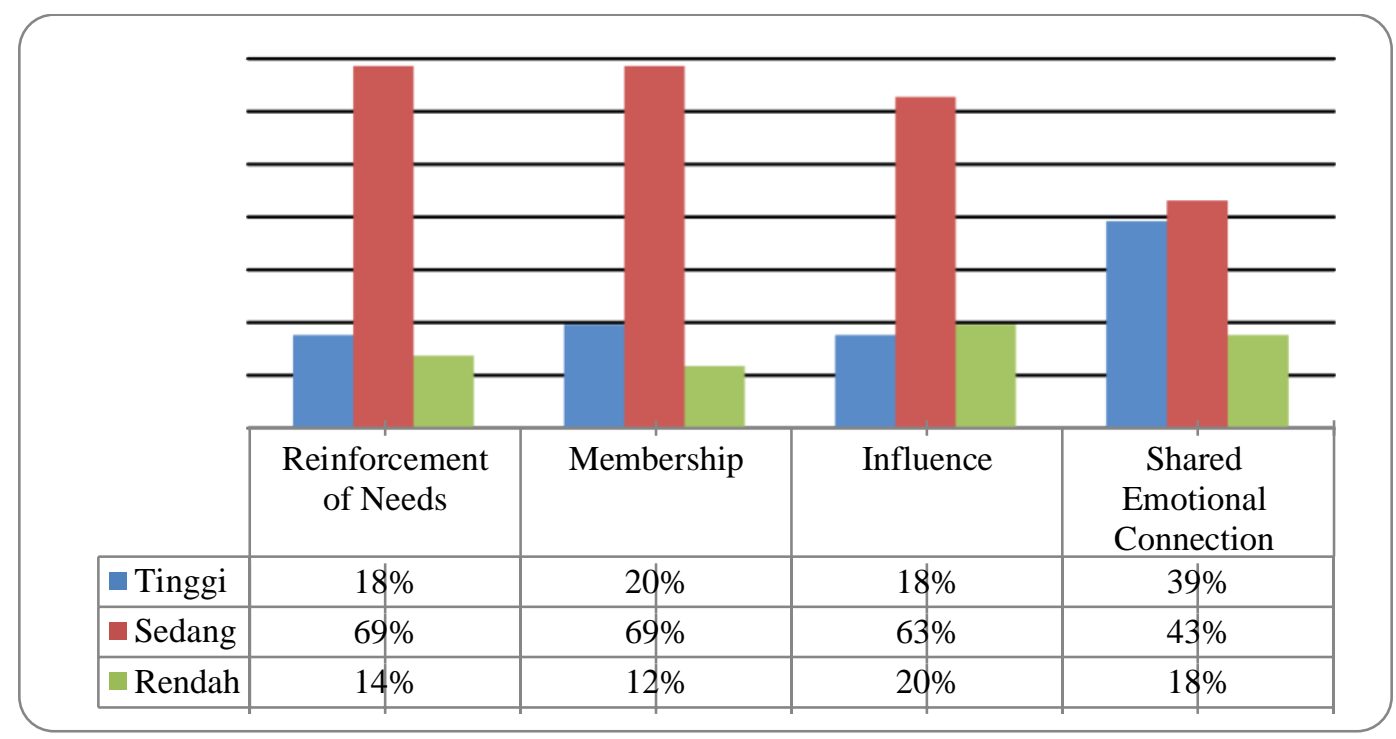

Gambar 6. Kategorisasi masing-masing aspek dalam sense of community

Selanjutnya untuk dimensi atau aspek SoC yang berada pada urutan ketiga dalam penelitian ini adalah dimensi atau aspek influence sekaligus dimensi integration and fullfillment of need (reinforcement of needs). Menurut McMillan dan Chavis (1968), menjelaskan bahwa aspek influence ini diartikan dalam dua sisi, pertama agar anggota kelompok bisa menonjol dalam kelompoknya maka harus memiliki pengaruh besar terhadap kelompoknya. Sisi lainnya, influence ini juga mengarah pada kemampuan kelompok untuk mempengaruhi anggotanya. Influence merupakan perasaan individu yang merasa bahwa dirinya berperan signifikan bagi kelompok atau komunitasnya. Terjadinya pengaruh anggota terhadap kelompoknya ataupun pengaruh kelompok terhadap anggotanya merupakan sebuah proses yang bisa terjadi secara bersamaan yang pada akhirnya menumbuhkan keeratan dalam kelompok. Selanjutnya untuk aspek integration and fullfillment of needs (reinforcement of needs), diartikan sebagai sebuah perasaan dimana anggota merasa bahwa kebutuhannya terpenuhi melalui sumbersumber yang berasal dari keanggotaan kelompoknya. Dalam aspek ini juga berkaitan erat dengan reinforcement, yakni penguatan atau penghargaan yang diberikan kelompok terhadap anggotanya sehingga terwujud kebersamaan yang positif antar anggota kelompok. Bentuk reinforcement yang bisa diperoleh anggota dari kelompoknya, berupa status, keberhasilan kelompok, kompetensi anggota, dan nilai 
yang dibagi antar anggota (shared values). Status menjadi anggota dalam kelompokmampu mendorong menguatnya sense of community pada anggota. Kompetensi yang dimiliki oleh anggota bisa digunakan untuk memenuhi kebutuhannya sehingga semakin menguatkan sense of community.

\section{SIMPULAN}

Berdasarkan hasil analisis data dalam penelitian ini bisa disimpulkan bahwa sense of community pada karyawan bagian administrasi di UMSIDA tergolong sedang. Jika dilihat dari keempat dimensi atau aspek sense of community yang digunakan sebagai alat ukur dalam penelitian ini, diketahui bahwa dimensi shared emotional connection menempati urutan tertinggi dibandingkan dimensi yang lain.

\section{DAFTAR PUSTAKA}

Amin, Defryansyah. (2015). Studi Mengenai Gambaran Sense Of Community Pada Pemain Game Online Yang Tergabung Dalam Guild/Clan. Fakultas PsikologiUniversitas Padjadjaran. Diunduh pada tanggal 25 Oktober 2016 dari https://scholar.google.co.id.

Falatehan, Sriwulan Ferindian. (2017). Pendekatan Psikologi Komunitas Dalam Memprediksi Peranan Rasa Memiliki Komunitas Terhadap Munculnya Partisipasi Masyarakat. Jurnal Ilmiah Psikologi MANASA, 6(1), 66-90. Diunduh pada tanggal 24
Februari 2018 dari https://scholar.google.co.id.

Irodah, Ajeng Bayyinatul, . Sense Of Community Pada Komunitas ExBank Duta Surabaya. Fakultas Ilmu Sosial dan Ilmu Politik-Universitas Airlangga. Diunduh pada tanggal 25 Oktober 2016 dari https://scholar.google.co.id.

Martinez, Asensio., Leiter, \& Gascon. (2017). Value Congruence, Control, Sense of Community and Demand As Determinants of Burnout Syndrome Among Hospitality Workers. International Journal of Occupational Safety and Ergonomics, 1-9. Diunduh pada tanggal 24 Februari 2018 dari https://scholar.google.co.id.

McMillan, David W. \& Chavis, David M. (1986). Sense of Community : A Definition and Theory. Journal of Community Psychology, 14, 6-23.

Neuman, W.Lawrence. (2013). Metodologi Penelitian Sosial : Pendekatan Kualitatif dan Kuantitatif. IndeksJakarta.

Patria, Fawzan Yahya. (2012). Hubungan Antara Sense Of Community Dengan Distres Psikologik Pada Warga Fakultas Psikologi Universitas Indonesia. Fakultas PsikologiUniversitas Indonesia. Diunduh pada tanggal 26 Oktober 2016 dari https://scholar.google.co.id.

Prayoga, Yande \& Herdiyanto, Yohanes Kartika. (2014). Hubungan Antara Rasa Komunitas Dengan Motivasi Kerja Pengurus Subak. Jurnal Psikologi Udayana, 1(2), 372-380.

Purwantika, Widiantisari. Setyawan, Imam. Ariati, Jati. (2014). Hubungan Antara Sense Of Community Dengan Prokrastinasi Akademik Pada Mahasiswa Fakultas Psikologi Universitas Diponegoro Semarang. Fakultas Psikologi-Universitas Diponegoro. Diunduh pada tanggal 
Psikologia (Jurnal Psikologi), 2 (1), January 2017, 52-64

ISSN 2338-8595 (print), ISSN 2541-2299 (online)

Journal Homepage: http://ojs.umsida.ac.id/index.php/psikologia DOI Link: 10.21070/psikologia.v2i1.756

$02 \quad$ Februari $2017 \quad$ dari https://scholar.google.co.id.

Rukmana, Ulil. (2015). Hubungan Antara Sense Of Community Dengan Kesiapsiagaan Psikologis Dalam Menghadapi Bencana Pada Guru Sekolah Dasar Di Kota Banda Aceh. Universitas Syah Kuala-Banda Aceh.
Diunduh pada tanggal 02 Februari 2017 dari https://scholar.google.co.id. Sarwono, Sarlito W \& Meinarno, Eko. (2009). Psikologi Sosial. Jakarta : Salemba Humanika.

Sugiyono. (2009). Metode Penelitian Kuantitatif, Kualitatif, dan $R \& D$. Alfabeta-Bandung. 